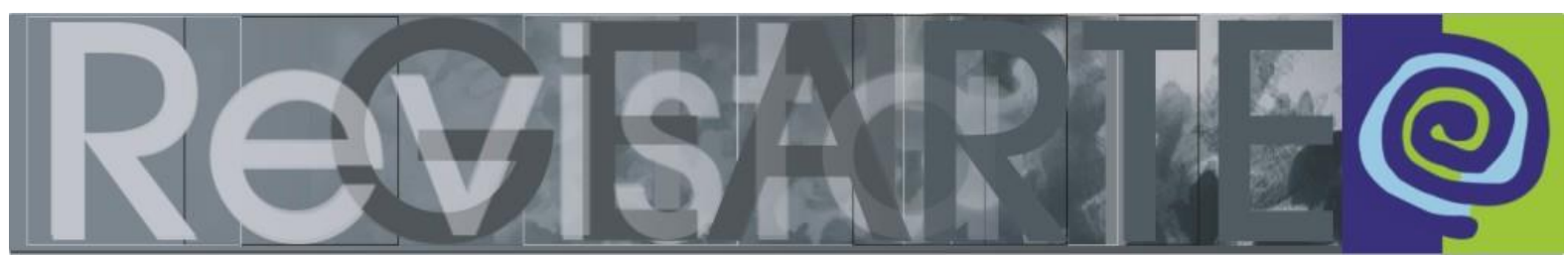

ISSN 2357-9854

\title{
Por que aprender cinema no hospital? \\ Experimentações com a sétima arte em contexto não formal de educação
}

\author{
Adriana Fresquet (Universidade Federal do Rio de Janeiro — UFRJ, \\ Rio de Janeiro/RJ, Brasil) \\ Fernanda Omelczuk (Universidade Federal do Rio de Janeiro — UFRJ, \\ Rio de Janeiro/RJ, Brasil)
}

\begin{abstract}
RESUMO - Por que aprender cinema no hospital? Experimentações com a sétima arte em contexto não formal de educação - $\mathrm{O}$ artigo tem como objetivo compartilhar algumas ressonâncias da aprendizagem de cinema no contexto hospitalar a partir do que identificamos como quatro potências: psicopedagógica, estética, ética e sociopolítica. Essas potências permitem-nos pensar tanto a experiência particular da qual partimos, como sinalizam a possibilidade de articulação entre os campos da Pedagogia Hospitalar, Classe Hospitalar e Ensino da Arte. Os conceitos de cinema, atividade criadora, aprendizagem da arte e educação no hospital que sustentam o trabalho estão em diálogo com Alain Bergala, Ana Mae Barbosa, Adriana Fresquet, Lev Vygotsky, Regina Fontes, dentre outros. Destacamos como reflexões futuras que, nesse contexto, os referenciais que trazemos mostram seus limites e nos impelem na invenção de outros enunciados para a Educação, para o fazer do professor, para o aprender e para as subjetividades.
\end{abstract}

PALAVRAS-CHAVE

Cinema e educação. Cinema no hospital. Pedagogia hospitalar.

RESUMEN - ¿Por qué aprender el cine en el hospital?Los ensayos con el séptimo arte en contexto no formal de la educación - El artículo tiene como objetivo compartir algunas repercusiones de aprendizaje del cine en el contexto hospitalario identificando cuatro fuerzas: psicopedagógica, estética, ética y socio-política. Estas fuerzas permiten nos pensar tanto en la experiencia particular que partimos, como apuntan la posibilidad de articulación entre los ámbitos de la Pedagogía Hospitalaria, la Escuela en el hospital y la Educación Artística. Los conceptos de cine, la actividad creadora, la educación artística y el aprendizaje en el hospital del trabajo están en diálogo con Alain Bergala, Ana Mae Barbosa, Adriana Fresquet, Lev Vygotsky, Regina Fontes. Destacamos a las futuras reflexiones que, en este contexto, las referencias que tenemos muestran sus límites e promueven la invención de otros pensamientos para la educación, para hacer del maestro, del aprender y de las subjetividades.

PALABRAS-CLAVE

Cine y educación. Cine en el hospital. Pedagogía hospitalaria.

\section{Introdução}

As experiências com a sétima arte no ambiente hospitalar que serão analisadas neste trabalho integram as práticas do grupo de pesquisa e extensão Cinema para 
Aprender e Desaprender - CINEAD ${ }^{1}$, que desde 2006 realiza atividades de fruição e criação cinematográfica com professores e alunos de escolas públicas no Rio de Janeiro. Em 2011 o CINEAD expandiu suas ações junto a crianças hospitalizadas do Instituto de Puericultura e Pediatria Martagão Gesteira - IPPMG - hospital pediátrico da Universidade Federal do Rio de Janeiro (UFRJ). Neste artigo, temos como objetivo compartilhar algumas ressonâncias da aprendizagem de cinema neste contexto específico a partir do que identificamos como quatro potências do cinema dentro do ambiente hospitalar: a potência psicopedagógica, a potência estética, a potência ética e a potência sociopolítica.

O projeto Cinema no hospital? - como é denominado - acontece semanalmente nas enfermarias do IPPMG, tendo como principais atividades a projeção de filmes com o suporte de um projetor e uma tela grande (ou projeções sobre as cortinas fechadas) e a realização de exercícios audiovisuais. As crianças podem assistir os filmes de suas próprias macas ou sentar-se em cadeiras posicionadas entre os leitos. Depois da exibição, dependendo das condições da ambiência hospitalar e da predisposição das crianças, são realizadas atividades de criação cinematográfica.

O artigo está organizado em quatro subitens, sendo o último de considerações finais. No primeiro, apresentaremos algumas das principais discussões acerca da educação das crianças no contexto hospitalar. Em seguida, abordaremos nosso ponto de vista sobre o cinema, o modo como trabalhamos e nossa proposta pedagógica para uma educação não formal no hospital, descrevendo as principais atividades realizadas. Na terceira parte, destacaremos quatro potências da sétima arte nesse espaço. E terminaremos o texto com algumas reflexões e pensamentos futuros.

\section{Algumas considerações sobre a educação (formal e não formal) no hospital}

Há no Brasil duas correntes teóricas que pensam a educação no hospital. Uma defende a continuidade da escolarização das crianças internadas seguindo os moldes do ensino formal, e a forma para isso é a organização de Classes Hospitalares. A

1 Mais informações em: <cinead.org $>$. 
outra, denominada Pedagogia Hospitalar, sugere que a prática pedagógica a ser desenvolvida nesse ambiente deve se inspirar nas características próprias do tempo, espaço e rotina hospitalar, e que os conhecimentos que contribuem para o bem estar físico, psíquico e emocional da criança não são necessariamente aqueles do currículo formal (FONTES, 2008).

Do ponto de vista formal, a Educação no hospital é reconhecida como direito da criança e do adolescente hospitalizado desde 1995, tanto por meio de programa de educação para a saúde quanto por acompanhamento do currículo escolar no modelo de classe hospitalar, prevista pela Política Nacional de Educação Especial (MEC/SEESP, 1994). Pesquisas realizadas por Ceccim e Fonseca (1999) mostraram que a frequência à classe hospitalar repercute na diminuição do tempo de internação e contribui para um melhor desenvolvimento cognitivo-afetivo. Apontam também que a classe hospitalar colabora para que a criança construa uma visão positiva de si e da experiência que está vivendo.

Paula (2005), entretanto, objeta que apenas as crianças que permanecem um longo período internadas se beneficiam das classes hospitalares, sendo necessária uma abordagem que propicie uma aprendizagem mais integrada com o "aqui e agora" das crianças que passam pouco, porém um intenso período nessas condições. É nesse sentido que a Pedagogia Hospitalar defende uma educação não formal de construção de conhecimentos sobre o hospital, entendendo este como um outro contexto de aprendizagem que não pode reproduzir as mesmas características da escola (TAAM, 2000).

Pensadores dessa segunda corrente entendem que a atitude de descoberta da realidade hospitalar rompe com fantasmas, medos, ansiedades e ajuda a criança a se sentir integrada e familiarizada com uma experiência até então desconhecida. Essa aprendizagem permitirá à criança se apropriar do espaço hospitalar, ressignifica-lo e reinventa-lo.

Fontes (2008) considera a Pedagogia Hospitalar mais abrangente que a Classe Hospitalar, pois a primeira comporta a classe hospitalar para determinadas situações, mas sinaliza a necessidade de outras abordagens, práticas e objetivos em outros 
casos. A autora argumenta também que pensar a Educação no hospital sob esse prisma é uma oportunidade de reflexão e transformação dos modos tradicionais de educação formal.

Foi em meio a esse campo e seus desafios que adentramos, colocando-nos algumas das seguintes reflexões: como o cinema pode contribuir para transformar o período de internação em experiências de aprendizagem, construção de conhecimento e reinvenção de significados, tal como propõe a Pedagogia Hospitalar? Como as experiências de cinema nos ajudam a pensar a educação que já acontece nesse espaço para além das práticas formais? Como elas poderiam ressignificar as experiências no hospital? Tentaremos atravessar por essas questões nas linhas abaixo.

\section{Educação, sétima arte e aprendizagem: diferentes enquadramentos}

Pauta recente de discussões entre educadores, psicólogos, pais e profissionais da mídia é a relação da criança com as imagens e o audiovisual, concentrando-se na influência que seus conteúdos, teores pedagógicos e morais exercem sobre desejos e pensamentos infantis. Essas são discussões importantes, mas observamos que deixam de fora a relação das crianças com o cinema como um bem cultural e marca de um gesto de criação; dimensões igualmente educativas e constitutivas de suas subjetividades.

A maior parte das preocupações com as imagens e o audiovisual pouco refletem a intenção de democratizar o acesso a diferentes filmes sob pontos de vista estéticos e de linguagem, rítmicos, sonoros, de movimento, som, luz, fotografia, enquadramentos, disposição, entre outros. Enfim, as escolhas dos cineastas são ignoradas e naturalizadas como construções de uma realidade, realidade da qual se parte e que se altera em cada gesto criativo do ver e fazer da arte cinematográfica. Nesse sentido, Bergala (2008) considera curioso que a educação tenha tanta preocupação com a veiculação ideológica do cinema e o mesmo não acontece em relação à educação artística do homem.

Pensar que o cinema pode ser educativo é entender o cinema como um vetor de ideologia antes de tudo, isto é, o cinema pode ser perigoso, o perigo 
ideológico. O medo de valores nefastos que o cinema pode ser portador (violência, racismo etc.) mas não se tem medo da mediocridade e da nulidade artística (BERGALA, 2008, p.45).

Compartilhando das reflexões do autor, tomamos as imagens em movimento do cinema como arte, pensando a relação da sétima arte com a educação a partir de sua metodologia - a pedagogia da criação- que aposta na experiência provocativa e desestabilizadora da alteridade do cinema (BERGALA, 2008).

Segundo Cohn (2013), a metodologia de trabalho do professor francês encontra pontos de convergência nos estudos e propostas contemporâneos de Arte-Educação, especialmente no que tange à Abordagem Triangular de Barbosa (2012) e às ações de ver, contextualizar e fazer. Ao pensar a aproximação da obra de arte pela leitura, pela contextualização e pelo fazer, Barbosa (2012) afirma a natureza tríplice da arte como linguagem, como produto social e como criação humana, todos passíveis de aprendizagem, reflexão e crítica - tarefas do educar. A arte, portanto, é um conhecimento que contempla tanto aspectos sensíveis quanto intelectuais.

Também seguindo essa reflexão, devido à presença de componentes "não racionais" no fazer artístico, Bergala (2008) entende que há algo no cinema que não pode ser "ensinado", fazendo-se necessária a experiência direta com o filme, com o fazer, com suas próprias reações e sensações. Identificamos, portanto, que proporcionar a oportunidade da própria criação entre os alunos é uma etapa presente tanto na proposta de Bergala (2008) para o cinema quanto na de Barbosa (2012) para o Ensino da Arte.

Para o autor, quando tomamos os filmes desde o ponto de vista da arte nos aproximamos do ato de criação, que é o modo como o cinema mostra e reconstrói o mundo. Após a reflexão e a análise -leitura da obra no Ensino da Arte e análise da criação na proposta de Bergala - o fazer é uma oportunidade do aluno entrar em contato com essa dimensão do saber que não é traduzível em palavras, mas que possui uma força de sentido e existência. 
Sensíveis a esses aspectos, parte central do projeto Cinema no hospital? é a realização de atividades de criação cinematográfica, cujas principais serão resumidas abaixo.

\section{Atividade um: Minutos Lumière}

O exercício consiste em filmar um único plano de um minuto, tendo como regras: câmera fixa; não poder editar, refilmar ou fazer zoom. Com essa atividade buscamos restaurar a própria infância do cinema, experimentar filmar como se fossemos os primeiros cineastas, como os irmãos Louis e August Lumière, a quem se reconhece consensualmente a invenção desta arte $^{2}$.

Atividade dois: filmado/ montado

O exercício é filmar diferentes planos ${ }^{3}$ pensando previamente na ordem dessa filmagem, isto é, "filmar montando" para contar uma história com 4 ou 5 planos. A regra do jogo consiste em não poder refilmar, isto é, se acontece algum erro ou problema, ele deve ser incorporado na narrativa. Essa atividade permite a realização de pequenos curta metragens pelos participantes sem a necessidade da edição ${ }^{4}$ das imagens por um programa de computador, pois a sequencia dos planos filmados já constitui uma história pronta para ser exibida.

Atividade três: cinco fotos, uma história

Bergala (2008) sugere esse exercício inspirado nas práticas de ensino do diretor de fotografia Jean-Luc Lhuillier, que o realiza com pessoas pouco familiarizadas com o cinema. A ideia é convidar a criança a criar uma história que

2 Para aprofundar sobre a história e metodologia deste e de outros dispositivos ler o capítulo 4 do livro Cinema e Educação: reflexões e experiências com estudantes de educação básica, dentro e "fora" da escola (FRESQUET, 2013a) e Currículo de cinema para Escolas de Educação Básica (FRESQUET et al, 2013b).

3 Plano é tudo o que acontece entre o ligar e desligar a câmera (MIGLIORIN et al., 2014).

4 Em uma linguagem analógica, podemos dizer que editar (ou montar) é um processo de "cortar" e "colar" as imagens em movimento, colocando-as lado a lado uma das outras, de modo a criar um sentido que surja dessa sequencia. 
aconteça no espaço imediato em que está e solicitar que tire 5 fotos para contar a história com essas imagens.

Atividade quatro: um objeto, diferentes pontos de vista

A proposta dessa atividade é que cada participante escolha um objeto e o fotografe de diferentes pontos de vista sem tirá-lo do lugar. Com esse exercício experimentamos que o ponto de vista é uma escolha dentre outras e nos perguntarmos como queremos que os outros vejam o que vemos. De que perspectiva estamos acostumados a ver o mundo? Existem outros modos de vê-lo? É possível alterá-lo ao enquadrá-lo de formas diferentes?

\section{Por que aprender cinema no hospital ${ }^{5}$}

\section{Potência psicopedagógica}

Seguindo nossos objetivos, organizamos exercícios audiovisuais nas enfermarias para que as crianças aprendessem a criar com elementos da sétima arte. Mas o que elas e suas produções foram nos mostrando é que ao aprenderem a filmar, a enquadrar, a escutar, outras aprendizagens podiam ser mobilizadas e novas subjetividades podiam ser produzidas no fluxo das vivências do coletivo. Como exemplo, queremos destacar a experiência de produção de um pequeno filme por um menino de oito anos, que mesmo em meio as censuras de sua mãe, avó e enfermeira, quis filmar a história de quando esteve no $\mathrm{CTI}^{6}$.

— "Tem outra história melhor, não?", perguntou a mãe. "No CTI? Mas isso já foi há muito tempo. Isso não é verdade" — reclamou a avó - "Você não sabe do que está falando. Isso não foi brincadeira não, tá?" — insistiu. "Não tinha outra história pra contar?" - perguntou a enfermeira.

Enquanto os adultos sussurravam sobre a "blasfêmia" que cometia, o menino não demonstrava dúvida de que habitava o "entre" lugar do real e da fantasia, para

5 Para aprofundar esta e outras questões sobre o tema sugerimos a leitura da tese $O$ que se aprende quando se aprende cinema no hospital? (OMELCZUK, 2016).

6 Disponível em: <https://vimeo.com/158805322>. 
onde se vai e volta como condição da própria sobrevivência humana. Ele então virou para uma delas e explicou o "óbvio" com sua simplicidade infantil: — "Vó, isso ai não é de verdade, um filme é só brincadeira". E observando que ela continuava a resmungar defendeu-se: - "Pô! Deixa eu contar a minha história!" O cinema deixa, — foi nossa reflexão em silêncio.

O menino insistiu em abrir espaço para suas imagens. No aprender e fazer cinema ele incorporou a doença, a hospitalização e os procedimentos médicos como elementos de criação audiovisual, fatos sobre os quais se pode falar, dar a ver, filmar, conversar e brincar. Nesse gesto, mostrou (ou revelou?) que a infância transita com mais fluidez que os adultos pelas fronteiras da crença e da dúvida, capacidade fundamental para uma relação criativa com as imagens do cinema (COMOLLI, 2008).

E nisso reside, entendemos nós, o fazer da infância, empoderado no encontro com a sétima arte e na possibilidade de inventar, criar e desorganizar o modus operandi de uma situação limite como a hospitalização. Qual o alcance dessas aprendizagens para a vida dessa criança em um sentido amplo, não formal, para além do hospital? Para além da escola?

A relação da criança com o cinema nos lembra a relação com o conhecimento nos dias de hoje. Uma criança para ver ou filmar faz escolhas, relaciona, toma decisões. Qual a relação com o conhecimento senão selecionar, estabelecer relações e decidir? E ainda, ambos acontecem em ambientes coletivos e colaborativos gerando produtos rapidamente multiplicados e compartilháveis.

Pensamos que essas e outras aprendizagens "colaterais" com o cinema no hospital afirmam uma narrativa distinta sobre o tempo da internação que afasta a criança da escola, instituição onde tradicionalmente se centraliza a educação e a aprendizagem. As experiências de cinema no hospital parecem ampliar os lugares do aprender. Elas democratizam a própria aprendizagem, a fruição estética e as condições para esses acontecimentos. 
Potência estética

Para Vygotsky (2012) o criar surge como uma necessidade do organismo, impulsionado por uma força inquieta, fruto da inadaptação com o meio. O rompimento de um equilíbrio que até então o homem mantinha com o ambiente gera emoções, necessidades, aspirações, desejos que "colocam em movimento o processo da imaginação" (VYGOTSKY, 2012, p. 41). Trata-se de uma ação que se mostra emergente em fases críticas do desenvolvimento, em situações de crise, por exemplo.

Sob esse prisma, pensamos que as crianças hospitalizadas vivem experiências que são por si só da ordem da invenção, já que experienciam uma situação de "desequilíbrio" e contradição com o meio que até então lhes era familiar, precisando se integrar e adaptar a uma nova realidade. Entender a hospitalização sob esse ponto de vista nos faz ver na experiência de internação algumas condições para a criação, por isso uma potência estética. Abaixo compartilhamos uma situação específica que ilustra essa compreensão.

Inspirados na leitura do texto Gennariello: a linguagem pedagógica das coisas, de Pier Paolo Pasolini que foi tema das reuniões do grupo de pesquisa do CINEAD em 2015, fizemos a seguinte atividade com as crianças da enfermaria: exibimos o filme O balão vermelho (1956), de Albert Lamorisse, que conta a história de amizade entre um menino e um balão e em seguida convidamos cada uma delas a escolher e filmar um único plano de 20 segundos de um objeto do hospital.

Neste texto, Pasolini (1990) compartilha suas memórias visuais mais antigas. Fala sobre os objetos da casa em que nasceu e em como aprendeu com eles sobre si e seu lugar social. As coisas, na sua opinião, possuem um discurso rígido e não verbal mais forte que as palavras. Elas falam de nós, falam para nós, educando-nos por completo em uma determinada ordem social.

Ainda que questionemos o determinismo inflexível que o cineasta atribui aos objetos, compartilhamos com ele que as "coisas" e o modo como estão arranjadas deixam suas marcas e também evocam memórias sobre o que vivemos e sentimos. Na situação de internação, onde os objetos são tão fortemente subjetivantes de uma 
nova condição social (bomba de medicação, seringas, utensílios para curativos, cateteres etc.), e a eficiência da rotina médica pode deixar as relações impessoais, pensar a relação das crianças com os objetos nos pareceu um modo de conhecer os desvios que se abrem nesse processo.

Que marcas esses objetos do hospital comunicam às crianças? Que marcas os objetos que as crianças trazem consigo para o hospital carregam? E que marcas pedagógicas os objetos que trazemos, como filmes, brinquedos ópticos e câmeras podem exercer sobre as crianças dentro do hospital? Como esses universos de "coisas" são integrados?

Queremos destacar a escolha de um menino de 10 anos que, respondendo ao convite da atividade, filmou sua bomba de medicação. Ao projetarmos seu plano na tela da enfermaria ouvimos alguns comentários dos adultos: "Aonde você vai ela vai atrás de você, né?". "É o seu balão".

O menino consentiu com os comentários, fazendo um ar de "sabichão", como se tivesse acertado a resposta de um exercício proposto. Tal como o balão vermelho persegue o protagonista no filme, a bomba de medicação o "persegue" no hospital. A relação entre o balão e a bomba de medicação surpreende pela simplicidade e pela poesia.

O que nos parece um exemplo de "percepção estética" sobre os artefatos do hospital que somente uma atenção distraída, de quem olha se permitindo também ser olhado, é capaz de acessar. Havia algo na experiência da relação do menino com este objeto que uma outra qualidade de atenção foi capaz de perceber. Isso nos faz refletir sobre a interrupção do curso da vida saudável demandar aprendizagem e redirecionamento da atenção para outros sentidos, materializando a força criativa que emana das situações de desequilíbrio e a importância de se abrir espaço para experiências desse caráter.

Potência ética

Entendemos que os períodos críticos de desenvolvimento da criança não são definidos apenas pela aparência traumática dos fatos, mas pelo que estes 
representam subjetivamente para ela. Se a criança lida com algo que não consegue explicar em uma atitude reflexiva, criando alternativas que a conduzam a um processo de busca permanente, (re) construindo representações diversas e anteriores, um novo momento qualitativo em seu desenvolvimento pode se abrir. Se a atitude frente a vivência não for consciente, mas mascarada e defensiva, pode haver danos a sua personalidade e saúde (REY, 1995).

O percurso por um ou outro caminho depende de sua interação com o ambiente, das respostas dos sujeitos com quem se relaciona, de sua capacidade de se apropriar da situação e reafirmar-se no meio. É nesse contexto que as atividades de criação cinematográfica se mostram como experiências de aprendizagem sobre o novo ambiente, reinvenção de significados, passagem da condição de paciente para agente - o que se reflete na abertura para produção de outras subjetividades.

Destacamos, por exemplo, a potência ética do gesto de enquadrar: fundamento das principais atividades de criação que realizamos no hospital. Realizar um plano, por exemplo, é destacar uma figura em meio a um fundo, num gesto de descoberta daquilo que nos afeta. Ao enquadrar desfazemos determinadas relações e criamos outras. No plano escolhemos o que queremos que se faça visível e invisível, dentro e fora. Enquadrar é emoldurar e valorizar, o que designa o encaminhamento de um modo de olhar, conferindo um valor diferenciado àquilo se faz ver (AUMONT, 1993).

Esse gesto nos parece especial dentro do hospital - uma estrutura que traz em sua ambiência as marcas da exclusão que impulsionaram sua invenção. Nascido como uma região para ocupar o lado de fora do enquadramento, onde ficava tudo o que não se queria ver: o pobre, o doente, a morte, o fim, os restos... enquadrar dentro desse espaço pode ser considerado um gesto político, já que implica emoldurar o que outrora foi deixado do lado de fora, isto é, levar o proibido para o interior do enquadramento. $\mathrm{O}$ que os enquadramentos dentro de um hospital podem nos fazer ver? O que vemos com as crianças?

As atividades de criação no hospital nos colocam junto às crianças em suas macas, nos dão a perspectiva de suas alturas na vista pela janela, nos vestem com suas máscaras, nos aproximam de suas bombas de medicação - a câmera nos 
empresta seus olhos. Com as experiências de cinema podemos vislumbrar um pouco o invisível, pensar o impensado e ouvir o inaudível que atravessa o dia a dia no hospital $^{7}$.

\section{Potência sociopolítica}

Se olharmos para o número de crianças participantes em um único encontro que fazemos nas enfermarias (quando comparado, por exemplo, com uma sala de aula que pode comportar mais de 30 crianças) o alcance quantitativo do projeto Cinema no hospital? poderia desanimar (as enfermarias, em seu limite, recebem 12 crianças). Em contraponto, um aspecto que nos parece diferencial neste contexto não formal de educação é a reverberação da ação pedagógica com os adultos que também transitam por esse espaço.

Diante das manifestações de surpresa e interesse dos "mais velhos" pelas filmografias desconhecidas, vislumbramos que o alcance pedagógico do cinema no hospital ultrapassa aquele instante e tem mais chance de se atualizar para além do hospital do que se a ação ocorresse em um ambiente em que pais e profissionais não estão juntos. São os responsáveis que consomem, trocam, indicam filmes para ir ao cinema ou assistir em casa. Eles participam na escolha do que vem condicionando a formação do gosto e influenciam a atitude das crianças diante das diferentes estéticas. Iniciativas de educação e cultura não podem ausentar-se desse espaço, sob o risco de ser ocupado por interesses do mercado.

Apontamos esse aspecto porque trabalhamos com a hipótese de que aquilo que as crianças e jovens apresentam como um gosto e escolha pessoal é muitas vezes a imposição de uma estética audiovisual midiática e comercial. Por isso, os filmes que exibimos são selecionados com vistas a ampliar o acesso à variedade de obras, possibilitando a reconfiguração do gosto, que é a possibilidade de ampliação da escolha: o que entendemos como uma das tarefas da educação (FRESQUET, 2013a).

Exercícios disponíveis em: <https://vimeo.com/158814920>; <https://vimeo.com/158816783>; <https://vimeo.com/158819330>; <https://vimeo.com/158820397>; <https://vimeo.com/158822679>. 
Nesse sentido, defendemos que trabalhos de educação e cinema para a infância envolvam atividades e intervenções também com esse público. Os pais costumam ser difusores acalorados do que aparece de novo e interessante para as crianças, colocando rapidamente em seus vínculos sociais a circulação dos materiais, produtos e tudo o que descobrem, numa proliferação pedagógica de proporções micropolíticas ainda mais potentes do que ações culturais restritas às crianças. $O$ hospital pode ainda ser cenário para cumprir de um modo diferente o quê a lei 13.006 vem solicitando à escola básica desde junho de 2014: projetar duas horas de cinema nacional por mês, como carga curricular complementar. (FRESQUET, 2015; FRESQUET et al., 2016).

\section{Considerações finais e pensamentos (presentes) futuros}

As potências psicopedagógicas, estéticas, éticas e sociopolíticas que buscamos compartilhar ajudam-nos a expor por um lado, a atitude imediata do que nossa experiência particular, hoje, com o cinema é capaz de tocar. Mas ao mesmo tempo, sinalizam para um futuro próximo a possibilidade de mais diálogos entre os campos da Pedagogia Hospitalar, da Classe Hospitalar e do Ensino da Arte, que podem contribuir para o desenvolvimento de novas reflexões e propostas para a Educação não formal como um todo. Presente e futuro, portanto, podem ser articulados por essas potências.

Isso porque pesquisar o cinema no hospital valoriza a ênfase de uma educação do presente para além de qualquer "preparação para o futuro". Ao mesmo tempo em que esse futuro se reconfigura na própria vida do paciente-aprendente, que quer aprender hoje não apenas em vistas de uma profissão ou ofício, mas apostando na continuidade da sua própria vida. Estudar para o amanhã, por exemplo, constitui uma forma de perspectivar seu caminho, de apostar na melhoria da saúde, na realização de sonhos e projetos. Acreditar que aprender é necessário e possível cria um vínculo inventivo entre o hoje e o amanhã costurado pelos fios do que se está aprendendo aqui e agora.

Será que essas considerações nos permitiriam pensar o hospital e o cinema como territórios de educação e formação docente? As condições "sob controle" para 
aprendizagem e o aluno em perfeito estado emocional e social para aprender, tal como nos mostram algumas leituras teóricas, contrastam no hospital com a realidade. Os saberes tradicionais sobre como se aprende, o que se aprende ou o que é importante aprender entram em suspensão. No encontro com o diferente, os referenciais que trazemos mostram seus limites e nos impelem na busca por novos enunciados. Assim nos transformamos e olhamos para velhas ideias, de um outro jeito, transformandoas também.

\section{Referências}

AUMONT, Jacques. A imagem. Campinas, SP: Papirus, 1993.

BARBOSA, Ana Mae. A imagem no ensino da arte. São Paulo: Perspectiva, 2012.

BERGALA, Alain. A hipótese-cinema: pequeno tratado de transmissão do cinema dentro e fora da escola. Rio de Janeiro: Booklink; CINEAD-LISE-FE/UFRJ, 2008.

BRASIL. Ministério da Educação e do Desporto. Secretaria de Educação Especial. Política Nacional de Educação Especial. Brasília, DF, 1994. (Mensagem especial; v. 1)

CECCIM, Ricardo; FONSECA, Eneida. Atendimento pedagógico-educacional hospitalar: promoção do desenvolvimento psíquico e cognitivo da criança hospitalizada. Temas sobre desenvolvimento, São Paulo, v. 7, n. 42, p. 24-36, 1999.

COHN, Greice. O ensino contemporâneo da arte e a hipótese de Bergala: diálogos e convergências. Pro-Posições, Campinas, v. 24, n. 1 (70), p.179-199, jan./abr. 2013.

COMOLLI, Jean. Ver e poder: cinema, televisão, ficção, documentário. Belo Horizonte: UFMG, 2008.

FONTES, Regina. Da classe à pedagogia hospitalar: a educação para além da escolarização. LINHAS, Florianópolis, v. 9, n. 1, p. 72- 92, jan./jun. 2008.

FRESQUET, Adriana. Cinema e educação: reflexões e experiências com estudantes de educação básica, dentro e "fora" da escola. 1. ed., Rio de Janeiro: Autêntica, 2013.

FRESQUET, Adriana (Org.). Currículo de cinema para escolas de educação básica. 2013. Disponível em: <www.cinead.org/materiais didáticos>. Acesso em: 8 jul. 2016.

FRESQUET, Adriana. (Org.). Cinema e educação: a lei 13006: reflexões, perspectivas e propostas. Belo Horizonte: Autêntica, 2015.

FRESQUET, Adriana et al. Proposta do Grupo de Trabalho Cinema Escola sobre Formação Docente. In: CINEOP, MOSTRA DE CINEMA DE OURO PRETO, 11, Ouro Preto. 2016. Cinema Patrimônio. Junho 2016. Ouro Preto: Universo, 2016.

MIGLIORIN, Cezar et al. (Coord.). Inventar com a diferença: cinema e direitos humanos. Universidade Federal Fluminense; Secretaria de Direitos Humanos e Ministério da Cultura. Niterói: UFF, 2014. Disponível em: $<$ http://www.inventarcomadiferenca.org/sites/defaultfiles/arquivos/Inventar_com_a_Diferenca_UFF.pdfs.

Acesso em: 10 ago. 2016.

OMELCZUK, Fernanda. O que se aprende quando se aprende cinema no hospital? Rio deJaneiro: UFRJ, 2016. Tese (Doutorado em Educação) — Programa de Pós-graduação em Educação, Faculdade de Educação, Universidade Federal do Rio de Janeiro, Rio de Janeiro, 2016.

PASOLINI, Pier P. Os jovens infelizes. São Paulo: Editora Brasiliense, 1990.

PAULA, Ercília. Educação, diversidade e esperança: a práxis pedagógica no contexto da escola hospitalar. Salvador: UFBA, 2005. Tese (Doutorado em Educação) - Programa de Pós-Graduação em Educação, Faculdade de Educação, Universidade Federal da Bahia, Salvador, 2005. 
REY, Fernando. Comunicación, personalidad y desarrollo. Editorial Pueblo y Educación: La Habana, 1995.

TAAM, Regina. Assistência pedagógica à criança hospitalizada. Niterói: UFF, 2000. Tese (Doutorado em Educação) - Programa de Pós-Graduação em Educação, Faculdade de Educação, Universidade Federal Fluminense, Niterói, 2000.

VYGOTSKY, Lev. Imaginación y creación en la edad infantil. Lanús Oeste: Nuestra América, 2012.

\section{Filmografia}

O balão vermelho. Produção e Direção: Albert Lamorisse. França. 1956.

\section{Adriana Fresquet}

Professora da Faculdade de Educação da Universidade Federal do Rio de Janeiro e membro do Programa de Pós-Graduação em Educação (FE/UFRJ). Coordena o grupo de pesquisa Currículo e Linguagem Cinematográfica na Educação Básica do Laboratório de Educação, Cinema e Audiovisual (LECAV). É membro fundador da Rede KINO: Rede Latino-Americana de Educação, Cinema e Audiovisual. Coordena a coleção Alteridade e Criação da Editora Autêntica, inaugurada com os livros Cinema e Educação e Godard e Educação e da coleção Cinema e Educação da Editora Booklink/UFRJ junto ao Hernani Heffner (MAM-Rio/PUC-Rio).

E-mail: adrianafresquet@gmail.com

Curriculo lattes: http://buscatextual.cnpq.br/buscatextual/busca.do

\section{Fernanda Omelczuk}

Doutora em Educação e professora substituta da Faculdade de Educação (FE/UFRJ). Membro do grupo de pesquisa CINEAD (Cinema para Aprender e Desaprender), do Laboratório de Educação, Cinema e Audiovisual (LECAV) da UFRJ.

E-mail: fernandaow@gmail.com

Curriculo lattes: http://buscatextual.cnpq.br/buscatextual/busca.do

Recebido em 14 de agosto de 2016 Aceito em 03 de dezembro de 2016 